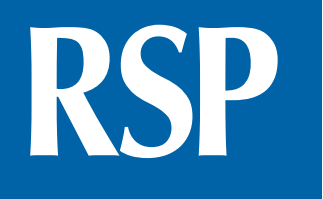

http://www.rsp.fsp.usp.br/

Revista de

Saúde Pública

\title{
Years of life lost by CNCD attributed to occupational hazards in Brazil: GBD 2016 study
}

\author{
Ada Ávila Assunção' (iD, Elisabeth Barboza França' \\ I Universidade Federal de Minas Gerais. Faculdade de Medicina. Programa de Pós-graduação em Saúde Pública. \\ Belo Horizonte-MG, Brasil
}

\begin{abstract}
OBJECTIVE: To assess the years of life lost due to premature death and disability-adjusted life years (DALY) as a result of chronic noncommunicable diseases attributable to occupational hazard factors, and to compare their position according to the risk ranking for chronic noncommunicable diseases in 1990 and 2016.

METHODS: Data for the DALY indicator, estimated from the Global Burden of Disease 2016 (GBD 2016) study, were analyzed for noncommunicable chronic diseases attributable to occupational, and other risk factors, selected in Brazil. A descriptive analysis was performed comparing the proportion of DALY by sex and age group ( 15 to 49 and 50 to 69 years old), as well as the ranking of occupational hazard factors in 1990 and 2016.
\end{abstract}

RESULTS: In 2016, ergonomic risk factors, carcinogenic agents, and noise in the workplace were among the 25 largest contributors to DALY for chronic noncommunicable diseases affecting the age group between 15 and 49 years. The contribution of all occupational hazard factors increased in 2016, except for occupational aerodispersoids affecting men. Concerning the age group between 50 and 69, occupational carcinogens stand out, with an increase of $26.0 \%$ for men, and $17.1 \%$ for women in 2016. Risk factors evaluated according to their 1990 and 2016 ranking show that occupational hazards have all scored higher on the second evaluation (2016), especially when compared with other risks.

Correspondence:

Ada Ávila Assunção

Av. Alfredo Balena n. 190, sala 705.

CEP 30130-100. Belo Horizonte,

MG, Brasil

E-mail: avilaufmg@gmail.com

Received: Out 6, 2018

Approved: Aug 13, 2019
CONCLUSIONS: The global burden of chronic noncommunicable diseases attributed to occupational hazard factors has become increasingly important. We suggest the strengthening of the approach of occupational hazard factors in the agendas for tackling these diseases in Brazil.

DESCRIPTORS: DALY; Occupational hazard factors; Brazil; Workers' health.

How to cite: Assunção AA, França

EB. Years of life lost by CNCD

attributed to occupational hazards

in Brazil: GBD 2016 study. Rev

Saude Publica. 2020;54:28.

Copyright: This is an open-access article distributed under the terms of the Creative Commons Attribution License, which permits unrestricted use, distribution, and reproduction in any medium, provided that the original author and source are credited. 


\section{INTRODUCTION}

Noncommunicable chronic diseases (NCD) cause 41 million deaths worldwide. Each year, 15 million people aged 30 to 69 die from cardiovascular disease, cancer, chronic respiratory disease, and diabetes. Poor/inadequate diet, physical inactivity, alcohol abuse, and smoking are behaviors that increase the risk of CNCD. These modifiable risk factors are addressed in Brazil by the Strategic Action Plan to Combat $\mathrm{CNCD}^{\mathrm{a}}$, which is in line with the guidelines of the World Health Organization (WHO) ${ }^{1}$.

CNCD are disabling. Under the Brazilian Social Security (BSS), in 2016, musculoskeletal diseases were the main cause of leave from work, which justified 407,000 sick leaves, followed by digestive tract diseases $(279,000)$, mental illness $(185,000)$, neoplasms $(165,000)$, and diseases of the circulatory system $(159,000)^{b}$.

There is evidence of an association between these diseases and occupational hazard factors $^{2,3,4,5}$. In general, they are cross-sectional studies conducted on samples of workers from a branch or production sector (the plastics industry ${ }^{2}$, for example) or specific occupational categories such as bus drivers ${ }^{3}$ or healthcare professionals ${ }^{5}$. These and other studies were commented in a recent review article, in which the authors systematized results of occupational surveys conducted in the last decade to obtain an overview of both the contribution and the gaps in knowledge about the health of Brazilian workers, as well as indicating challenges in the public health field ${ }^{6}$. Among the gaps and challenges are the difficulties in estimating risks due to multiple exposures in the workplace, as well as the under-registration related to the current labor market configuration. The complexity related to multiple exposures, in which combination and sometimes synergy of effects occurs, requires sophisticated statistical designs and methods when the objective is to identify risks and monitor work situations. For these and other reasons, the burden resulting from occupational hazards is not yet sufficiently measured or broadly characterized ${ }^{7}$. As for under-registration, its origin lies within the incompleteness or lack of information on health profiling, employment characteristics, and occupational exposure. The coverage gaps in the employment information system are marked by the increasing proportion of people employed without a formal contract: $82.9 \%$ to $50.7 \%$, as observed in Maranhão and Santa Catarina, respectively ${ }^{\mathrm{c}}$. Knowing that $24.2 \%$ of Brazilian adults have

a Brasil. Ministério da Saúde. Secretaria de Vigilância em Saúde. Departamento de Análise de Situação de Saúde. Plano de ações estratégicas para o enfrentamento das doenças crônicas não transmissíveis (DCNT) no Brasil 2011-2022 / Ministério da Saúde. Secretaria de Vigilância em Saúde. Departamento de Análise de Situação de Saúde. - Brasília: Ministério da Saúde, 2011. Acesso 28 Ago 2018.

${ }^{\mathrm{b}}$ Ministério da Fazenda. Anuário Estatístico da Previdência Social/Ministério da Fazenda. Secretaria de Previdência, Empresa de Tecnologia e Informações da Previdência. Brasília: MF/DATAPREV, 2016. Acesso 22 Fev 2019.

c Brazilian Institute of Geography and Statistics. Summary of social indicators: an analysis of the living conditions of the Brazilian population: 2016 / IBGE, Population Coordination and Social Indicators. - Rio de Janeiro: IBGE, 2016. Access Feb 24, 2019. more than one chronic disease ${ }^{8}$, how does one obtain quality information to formulate actions to monitor and prevent CNCD associated with occupational hazard factors?

The study Global Burden of Disease (GBD) has produced comprehensive assessments of human health since the 1990s. The main metric used in the GBD study was the disability-adjusted life years (DALY). This indicator, in a single measure, expresses the years lost due to illness, that is, the years of life lost due to premature death, and the unhealthy years spent living with a disability. The calculation of this indicator is based on a scale ranging from zero to one, where zero designates the state of full health and one designates death, the worst possible state of health. Life years lost due to death are calculated by reference to life expectancy estimated from the lowest mortality rates for each age group in locations with more than five million inhabitants. The years of life lost (YLL) are added to the years lived with disability (YLD) employing a scale that associates mortality, disease, and their sequelae .

In addition to measuring health loss, the GBD study examines three risk factor (RF) groups. For each of those selected, the population attributable risk (PAR) is calculated, which measures the disease burden attributable to certain exposures ${ }^{10}$. PAR allows the identification, for example, of what index of the total risk for fatal lung cancer in the general population is due to occupational hazards.

This study aimed at using estimates from the GBD 2016 study to assess healthy years of life lost due to premature death and CNCD disability attributable to occupational hazard factors and comparing their position in risk ranking in 1990 and 2016. 


\section{MATERIAL AND METHODS}

\section{Research Context}

The conceptual, methodological and operational advancement promoted by the GBD study results from the institutional efforts of 195 countries and territories, in addition to having powerful computational resources (big data) and funding provided by the Bill \& Melinda Gates Foundation ${ }^{9}$. To identify both health risks and health degradation by disease and injury, the study elaborates on complex strategies for combining data from different sources. The selected risks are evaluated in an articulated manner, to identify them according to age, sex, and geographical area.

Since the Disease Burden workshop in Brazil in 2014, public health professionals and researchers have been involved in the partnership between the University of Washington Institute for Health Metrics and Evaluation (IHME) ${ }^{10}$, the Brazilian Ministry of Health, and the Universidade Federal de Minas Gerais (UFMG). The use of the metrics elaborated by the GBD study was one of the impulses for Brazilian institutions in joining this network ${ }^{11}$. The dissemination of the methodology reached the academic environment and health services to motivate, among others, the elaboration of this article.

\section{GBD Study Estimates}

The GBD study estimates result from a complex process of modeling primary sources as detailed in previous publications ${ }^{12}$. Specific software was developed to estimate mortality (CODEM) and morbidity (Dis-mod), as well as technical devices for covariate adjustments (GDP, education, etc.). Estimates are shown with their respective uncertainty ranges. On the $\mathrm{IHME}^{10}$ website, the user can access all these estimates calculated through standardized methodology. According to the researcher's interest, it is possible to access data available from 195 countries, 20 age groups, both sexes, and three risk groups: environmental/occupational, metabolic and behavioral. The user has the option of choosing to view schematics and illustrative figures on the information according to year of observation, risk, and cause group.

As previously explained, the GBD study is concerned with population attributable risks (PAR), which calculate how the disease burden would have been reduced if exposure had been changed to a minimum level in the past, the so-called theoretical minimum risk exposure level (TMREL). TRMEL is considered an advanced construct as it uses the minimum exposure regarding the lowest theoretical exposure level. In addition to TMREL, PAR is based on two other components: relative risk and the prevalence of risk factors within the population. Relative risk estimates are based on consistent research results, such as randomized controlled trials, cohort studies, and others, providing they had been developed using appropriate methods 9 . Exposure levels and relative risks for each of the listed factors are measured according to available literature ${ }^{12}$. The prevalence of $\mathrm{RF}$ is estimated according to information from different types of surveys, such as those conducted at the respondent's home, or environmental measurements collected by different strategies, including satellites. Chart 1 shows the GBD study definitions for each occupational RF.

\section{Analysis Presented by this Article}

This descriptive study used the global burden of disease estimates for Brazil found on the GBD 2016 study, whose data are publicly available from the IHME $^{10}$ website, where all indicators are calculated and updated. The focus of this study was to observe the DALY indicator for CNCD, according to RF categorized up to the third level ${ }^{12}$. The proportions of healthy years lost for men and women were examined separately for two age groups: 15 to 49 years, and 50 to 69 years. This strategy enabled us to obtain the ranking of RF, which contributed most to the CNCD-related DALY indicator and the comparison of the 2016 results with those of 1990. 
Chart 1. Occupational hazard factor definitions assessed by the GBD study ${ }^{13}$

\begin{tabular}{|l|c|}
\hline Occupational asbestos & $\begin{array}{r}\text { Accumulated occupational exposure to asbestos according to the mortality } \\
\text { rate from pleural mesothelioma. }\end{array}$ \\
\hline $\begin{array}{l}\text { Bronchoconstrictor substances } \\
\text { in the occupational } \\
\text { environment }\end{array}$ & $\begin{array}{r}\text { The proportion of individuals exposed to bronchoconstrictors in the } \\
\text { occupational environment based on population distribution in nine } \\
\text { economic sectors. }\end{array}$ \\
\hline Occupational carcinogens & $\begin{array}{r}\text { The proportion of individuals in groups identified as exposed (high } \\
\text { and low exposures) to recognized carcinogenic agents (arsenic, acids, } \\
\text { benzene, beryllium, cadmium, chromium, diesel, formaldehyde, } \\
\text { nickel, polycyclic aromatic hydrocarbons, passive smoking, silica, } \\
\text { trichloroethylene), using as reference the population distribution in } \\
17 \text { economic sectors. }\end{array}$ \\
\hline Accidents at work & $\begin{array}{r}\text { The proportion of fatal accidents attributed to work activity in seventeen } \\
\text { economic sectors, regarding the rates recorded in each sector. }\end{array}$ \\
\hline Ergonomic factors & $\begin{array}{r}\text { The proportion of individuals exposed to low back pain risk factors, based } \\
\text { on population distribution in nine economic sectors. }\end{array}$ \\
\hline Occupational noise & $\begin{array}{r}\text { The proportion of individuals exposed to a sound intensity level exceeding } \\
85 \text { decibels in the occupational environment, using as reference the } \\
\text { population distribution in 17 economic sectors. }\end{array}$ \\
\hline $\begin{array}{l}\text { Aerodispersoid particles in the } \\
\text { occupational environment }\end{array}$ & $\begin{array}{r}\text { The proportion of individuals to a aerodisersoid particles, based on } \\
\text { population distribution in 17 economic sectors. }\end{array}$ \\
\hline
\end{tabular}

Figure 1. Major risk factors for noncommunicable diseases according to disability-adjusted life years (DALY) and to sex and age group. Brazil, 2016.

\begin{tabular}{|c|c|c|c|c|c|}
\hline \multicolumn{3}{|c|}{15 to 49 years old } & \multicolumn{3}{|c|}{50 to 69 years old } \\
\hline Men & Position & Women & Men & Position & Women \\
\hline Alcohol consumption & 1 & High body mass index & High blood pressure & 1 & High body mass index \\
\hline High body mass index & 2 & Alcohol consumption & High body mass index & 2 & High blood pressure \\
\hline High blood pressure & 3 & High blood glucose & Smoking habit & 3 & High blood glucose \\
\hline High total cholesterol & 4 & High blood pressure & High blood glucose & 4 & Smoking habit \\
\hline High blood glucose & 5 & Smoking habit & Alcohol consumption & 5 & High total cholesterol \\
\hline Drug use & 6 & Drug use & High total cholesterol & 6 & Alcohol consumption \\
\hline Smoking habit & 7 & High total cholesterol & $\begin{array}{l}\text { Nutritional deficiency in nuts } \\
\text { and seeds }\end{array}$ & 7 & Impaired kidney function \\
\hline $\begin{array}{l}\text { Nutritional deficiency in nuts } \\
\text { and seeds }\end{array}$ & 8 & Ergonomic risks & Impaired kidney function & 8 & $\begin{array}{l}\text { Nutritional deficiency in nuts } \\
\text { and seeds }\end{array}$ \\
\hline Ergonomic risks & 9 & Unprotected sex & Vegetable deficient diet & 9 & Vegetable deficient diet \\
\hline Vegetable deficient diet & 10 & Impaired kidney function & Particulate matter & 10 & Particulate matter \\
\hline Fruit deficient diet & 11 & $\begin{array}{l}\text { Nutritional deficiency in nuts } \\
\text { and seeds }\end{array}$ & High sodium diet & 11 & Sedentary lifestyle \\
\hline Impaired kidney function & 12 & Vegetable deficient diet & Fruit deficient diet & 12 & Occupational carcinogens \\
\hline Particulate matter & 13 & Fruit deficient diet & Occupational carcinogens & 13 & Fruit deficient diet \\
\hline Occupational carcinogens & 14 & Particulate matter & Sedentary lifestyle & 14 & Unprotected sex \\
\hline Fiber deficient diet & 15 & $\begin{array}{l}\text { Nutritional deficiency in } \\
\text { whole grains }\end{array}$ & $\begin{array}{l}\text { Nutritional deficiency in } \\
\text { Omega } 3\end{array}$ & 15 & High sodium diet \\
\hline $\begin{array}{l}\text { Nutritional deficiency in } \\
\text { Omega } 3\end{array}$ & 16 & Occupational carcinogens & Fiber deficient diet & 16 & $\begin{array}{l}\text { Nutritional deficiency in } \\
\text { whole grains }\end{array}$ \\
\hline High sodium diet & 17 & Fiber deficient diet & Passive smoking & 17 & $\begin{array}{l}\text { Nutritional deficiency in } \\
\text { Omega } 3\end{array}$ \\
\hline $\begin{array}{l}\text { Nutritional deficiency in } \\
\text { whole grains }\end{array}$ & 18 & Passive smoking & Ergonomic risks & 18 & Passive smoking \\
\hline Sedentary lifestyle & 19 & Sedentary lifestyle & $\begin{array}{l}\text { Nutritional deficiency in } \\
\text { whole grains }\end{array}$ & 19 & Fiber deficient diet \\
\hline Occupational noise & 20 & $\begin{array}{l}\text { Nutritional deficiency in } \\
\text { Omega } 3\end{array}$ & Lead exposure & 20 & Ergonomic risks \\
\hline Passive smoking & 21 & High sodium diet & Occupational noise & 21 & Drug use \\
\hline Lead exposure & 22 & Occupational noise & Drug use & 22 & Lead exposure \\
\hline
\end{tabular}


As CNCD, the GBD study includes cardiovascular diseases; malignant neoplasms; other malignancies; respiratory diseases; diabetes mellitus; musculoskeletal disorders; skin disorders; digestive disorders; mental and nervous system disorders; sensory organ disorders; genitourinary disorders; neurological conditions; congenital anomalies; oral conditions; and endocrine, blood and immunological dysfunctions ${ }^{13}$. It is noteworthy that data from the GBD 2016 study on morbidity for Brazil were extracted from national surveys, such as the National Health Survey (PNS), the Surveillance System for Risk and Protective Factors for Chronic Diseases by Telephone Survey (Vigitel), and the National Household Sample Survey (PNAD), among others, totaling 118 sources. For sources of occupational exposure, results from national workforce surveys, demographic studies, information from international systems on occupational exposure to carcinogens, data on occupational accidents available from the International Labor Organization database, and noise information were consulted, obtained from specific industrial surveys ${ }^{13}$.

The GBD Brasil project was approved by the Research Ethics Committee of the Universidade Federal de Minas Gerais, CAAE 62803316.7.0000.5149.

\section{RESULTS}

In 2016, within the age group 15 to 49 years considered productive, alcohol consumption and high BMI were the two main risk factors for DALY by CNCD. For men, alcohol consumption prevailed (13.28\%), and for women, high BMI (7.77\%). Concerning occupational hazards, ergonomic factors, carcinogenic agents, and noise stood out, in this order, for both sexes (Figure 1).

Figure 2A. Risk factors that most contributed to premature death and loss of health from chronic noncommunicable diseases among men aged 15 to 49. Brazil, 1990 and 2016.

\begin{tabular}{|c|c|c|c|c|}
\hline Men aged 15 to $49-1990$ & & Men aged 15 to $49-2016$ & $\%$ of the total DALY & Variation \\
\hline 1. Alcohol consumption & & 1. Alcohol consumption & $13.28 \%(11.78-14.97 \%)$ & $9.85 \%$ \\
\hline 2. Smoking habit & & 2. High body mass index & $9.24 \%(6.68-11.98 \%)$ & $11.73 \%$ \\
\hline 3. High blood pressure & & 3. High blood pressure & $7.1 \%(5.76-8.71 \%)$ & $-22.41 \%$ \\
\hline 4. High body mass index & & 4. High total cholesterol & $5.19 \%(4.3 \%-6.25 \%)$ & $-29.06 \%$ \\
\hline 5. High total cholesterol & & 5. High blood glucose & $4.65 \%(3.79-5.62 \%)$ & -8.81 \\
\hline 6. High blood glucose & & 6. Drug use & $4.62 \%(3.92-5.42 \%)$ & $30.7 \%$ \\
\hline 7. Vegetable deficient diet & & 7. Smoking habit & $4.48 \%(3.54 \%-5.56 \%)$ & $-57.05 \%$ \\
\hline 8. Fruit deficient diet & & 8. Nutritional deficiency in nuts and seeds & $2.96 \%(1.99 \%-4.03 \%)$ & $-25.66 \%$ \\
\hline 9. Nutritional deficiency in nuts and seeds & & 9. Ergonomic risks & $2.57 \%(2.03-3.23 \%)$ & $25.47 \%$ \\
\hline 10. Drug use & & 10. Vegetable deficient diet & $2.48 \%(1.26-3.82 \%)$ & $-43.51 \%$ \\
\hline 11. Ambient particulate matter & & 11. Fruit deficient diet & $2.27 \%(1.19 \%-3.54 \%)$ & $-48.33 \%$ \\
\hline 12. Impaired kidney function & & 12. Impaired kidney function & $1.99 \%(1.7-2.3 \%)$ & $-26.05 \%$ \\
\hline 13. Nutritional deficiency in Omega 3 & & 13. Ambient particulate matter & $1.71 \%(1.24-2.24 \%)$ & $-44.6 \%$ \\
\hline 14. Domestic air pollution & & 14. Occupational carcinogens & $1.23 \%(0.93-1.58 \%)$ & $11.89 \%$ \\
\hline 15. Ergonomic risks & & 15. Fiber deficient diet & $1.19 \%(0.66 \%-1.91 \%)$ & $-37.93 \%$ \\
\hline 16. Fiber deficient diet & & 16. Nutritional deficiency in Omega 3 & $1.1 \%(0.42-1.93 \%)$ & $-49.16 \%$ \\
\hline 17. Nutritional deficiency in whole grains & & 17. High sodium diet & $1 \%(0.015 \%-2.6 \%)$ & $84.64 \%$ \\
\hline 18. Sedentary lifestyle & & 18. Nutritional deficiency in whole grains & $0.95 \%(0.16 \%-2.19 \%)$ & $-33.64 \%$ \\
\hline 19. Occupational carcinogens & & 19. Sedentary lifestyle & $0.91 \%(0.48 \%-1.42 \%)$ & $-26.21 \%$ \\
\hline 20. Lead exposure & & 20. Occupational noise & $0.78 \%(0.61-0.98 \%)$ & $11.9 \%$ \\
\hline 21. Occupational noise & & & & \\
\hline
\end{tabular}

DALY: disability-adjusted life years 
Among men aged 15 to 49 years, ergonomic factors (2.57\% of DALY) rose from 15th position in 1990 to 9th position in 2016, showing a $25.47 \%$ increase in DALY. It is noteworthy that only the increase related to sodium-rich diets (84.64\%) and drug use (30.7\%) was greater than that related to ergonomic RF (Figure 2A). Among women (Figure 2B), the RF (2.11\%) rose from 14th to 8th position, corresponding to the largest increase (22.39\%) after the high-sodium diet (40.99\%). Occupational carcinogenic agents (1.23\%) among men increased from 19th to 14th position, showing an increase of $11.89 \%$ compared to 1990 (Figure 2A). Among women, the increase in total DALY was $9.54 \%$, causing the change from 20th to 16th position in 2016 (Figure 2B). In 2016, noise was the third occupational hazard in the ranking, which rose from 21st to 20th position among men (Figure $2 \mathrm{~A}$ ), and from 24 th to 22nd among women (Figure 2B) in the age group between 15 and 49 years. Compared with 1990, the increase in total DALY by CNCD attributable to occupational noise was greater for women $(20.38 \%)$ than for men (11.9\%).

In the age group between 50 and 69 years, high blood pressure and BMI are the main risks for DALY by CNCD. For men, high blood pressure (19.55\%) is the most relevant RF. For women, it is a high BMI (17.1\%). In this range, the following occupational hazards stand out in this order for both sexes: occupational carcinogenic agents, ergonomic factors, and noise (Figure 1).

Among men aged 50 to 69, occupational carcinogenic agents (2.97\%) rose from 16th position in 1990 to 13th position in 2016 (Figure 3A), with a DALY increase of $26.04 \%$. Among women in this age group, these risks (1.95\%) rose from 19th to 12th position (Figure 3B), showing an increase of $17.1 \%$. As for ergonomic factors, among men (1.18\%),

Figure 2B. Risk factors that most contributed to premature death and loss of health due to chronic noncommunicable diseases among women aged 15 to 49. Brazil, 1990 and 2016.

\begin{tabular}{|c|c|c|c|}
\hline Women aged 15 to $49-1990$ & Women aged 15 to $49-2016$ & $\%$ of the total DALY & Variation \\
\hline 1. High body mass index & 1. High body mass index & $7.77 \%(5.98 \%-9.51 \%)$ & $3.88 \%$ \\
\hline 2. Smoking habit & 2. Alcohol consumption & $4.23 \%(3.46 \%-5.1 \%)$ & $10.52 \%$ \\
\hline 3. High blood pressure & 3. High blood glucose & $3.86 \%(3.25 \%-4.54 \%)$ & $-10.53 \%$ \\
\hline 4. High blood glucose & 4. High blood pressure & $3.36 \%(2.6 \%-4.31 \%)$ & $-31.62 \%$ \\
\hline 5. Alcohol consumption & 5. Smoking habit & $2.91 \%(2.28 \%-3.63 \%)$ & $-54.93 \%$ \\
\hline 6. High total cholesterol & 6. Drug use & $2.33 \%(1.94 \%-2.75 \%)$ & $21.28 \%$ \\
\hline 7. Fruit deficient diet & 7. High total cholesterol & $2.23 \%(1.77 \%-2.76 \%)$ & $-32.54 \%$ \\
\hline 8. Vegetable deficient diet & 8. Ergonomic risks & $2.11 \%(1.7 \%-2.6 \%)$ & $22.39 \%$ \\
\hline 9. Impaired kidney function & 9. Unprotected sex & $1.66 \%(1.34 \%-2.05 \%)$ & $-11.11 \%$ \\
\hline 10. Nutritional deficiency in nuts and seeds & 10. Impaired kidney function & $1.63 \%(1.37 \%-1.95 \%)$ & $-28.6 \%$ \\
\hline 11. Drug use & 11. Nutritional deficiency in nuts and seeds & $1.47 \%(1 \%-2 \%)$ & $-26.43 \%$ \\
\hline 12. Unprotected sex & 12. Vegetable deficient diet & $1.41 \%(0.75 \%-2.15 \%)$ & $-47.91 \%$ \\
\hline 13. Particulate matter in the environment & 13. Fruit deficient diet & $1.36 \%(0.7 \%-2.2 \%)$ & $-53.2 \%$ \\
\hline 14. Ergonomic risks & 14. Particulate matter in the environment & $0.98 \%(0.71 \%-1.31 \%)$ & $-46.95 \%$ \\
\hline 15. Domestic air pollution & 15. Nutritional deficiency in whole grains & $0.9 \%(0.27 \%-1.77 \%)$ & $-29.49 \%$ \\
\hline 16. Nutritional deficiency in whole grains & 16. Occupational carcinogens & $0.71 \%(0.52 \%-0.93 \%)$ & $9.54 \%$ \\
\hline 17. Nutritional deficiency in Omega 3 & 17. Fiber deficient diet & $0.62 \%(0.36 \%-0.95 \%)$ & $-35.81 \%$ \\
\hline 18. Fiber deficient diet & 18. Passive smoking & $0.56 \%(0.42 \%-0.73 \%)$ & $-13.41 \%$ \\
\hline 19. Sedentary lifestyle & 19. Sedentary lifestyle & $0.53 \%(0.31 \%-0.79 \%)$ & $-24.73 \%$ \\
\hline 20. Occupational carcinogens & 20. Nutritional deficiency in Omega 3 & $0.51 \%(0.2 \%-0.88 \%)$ & $-48.93 \%$ \\
\hline 21. Passive smoking & 21. High sodium diet & $0.45 \%(0.00045 \%-1.42 \%)$ & $40.99 \%$ \\
\hline 22. Lead exposure & 22. Occupational noise & $0.4 \%(0.32 \%-0.5 \%)$ & $20.38 \%$ \\
\hline \multicolumn{4}{|l|}{ 23. Child sexual abuse } \\
\hline 24. Occupational noise & & & \\
\hline
\end{tabular}

DALY: disability-adjusted life years 
Figure 3A. Risk factors that most contributed to premature death and loss of health from chronic noncommunicable diseases among men aged 50 to 69. Brazil, 1990 and 2016.

\begin{tabular}{|c|c|c|c|c|}
\hline Men aged 50 to $69-1990$ & & Men aged 50 to $69-2016$ & $\%$ of the total DALY & Variation \\
\hline 1. Smoking habit & & 1. High blood pressure & $19.55 \%(17.57 \%-21.65 \%)$ & $-20.33 \%$ \\
\hline 2. High blood pressure & & 2. High body mass index & $15.93 \%(10.58 \%-21.43 \%)$ & $25.31 \%$ \\
\hline 3. High total cholesterol & & 3. Smoking habit & $13.62 \%(12.03 \%-15.24 \%)$ & $-45.89 \%$ \\
\hline 4. High body mass index & & 4. High blood glucose & $11.1 \%(9.37 \%-12.97 \%)$ & $3.9 \%$ \\
\hline 5. High blood glucose & & 5. Alcohol consumption & $11.05 \%(8.55 \%-13.49 \%)$ & $29.3 \%$ \\
\hline 6. Alcohol consumption & & 6. High total cholesterol & $9.62 \%(8.05 \%-11.29 \%)$ & $-27.26 \%$ \\
\hline 7. Vegetable deficient diet & & 7. Nutritional deficiency in nuts and seeds & $5.16 \%(3.49-7 \%)$ & $-21.35 \%$ \\
\hline 8. Nutritional deficiency in nuts and seeds & & 8. Impaired kidney function & $4.39 \%(4.01 \%-4.79 \%)$ & $-4.75 \%$ \\
\hline 9. Fruit deficient diet & & 9. Vegetable deficient diet & $4.28 \%(2.16 \%-6.56 \%)$ & $-39.45 \%$ \\
\hline 10. Particulate matter in the environment & & 10. Particulate matter in the environment & $3.75 \%(2.86 \%-4.72 \%)$ & $-39.16 \%$ \\
\hline 11. Impaired kidney function & & 11. High sodium diet & $3.32 \%(0.071 \%-7.87 \%)$ & $100.53 \%$ \\
\hline 12. Domestic air pollution & & 12. Fruit deficient diet & $3.29 \%(1.53 \%-5.4 \%)$ & $-47.93 \%$ \\
\hline 13. Nutritional deficiency in Omega 3 & & 13. Occupational carcinogens & $2.97 \%(2.41 \%-3.56 \%)$ & $26.04 \%$ \\
\hline 14. Sedentary lifestyle & & 14. Sedentary lifestyle & $2.67 \%(1.45 \%-4.03 \%)$ & $-26.51 \%$ \\
\hline 15. Fiber deficient diet & & 15. Nutritional deficiency in Omega 3 & $1.92 \%(0.72 \%-3.4 \%)$ & $-49.56 \%$ \\
\hline 16. Occupational carcinogens & & 16. Fiber deficient diet & $1.55 \%(0.82 \%-2.47 \%)$ & $-35.5 \%$ \\
\hline 17. Lead exposure & & 17. Passive smoking & $1.38 \%(1.07 \%-1.74 \%)$ & $-8.85 \%$ \\
\hline 18. High sodium diet & & 18. Ergonomic risks & $1.18 \%(0.83 \%-1.6 \%)$ & $30.7 \%$ \\
\hline 19. Nutritional deficiency in whole grains & & 19. Nutritional deficiency in whole grains & $1.16 \%(0.14 \%-2.92 \%)$ & $-25.76 \%$ \\
\hline 20. Passive smoking & & 20. Lead exposure & $1.01 \%(0.39 \%-1.7 \%)$ & $-48.64 \%$ \\
\hline 21. Occupational particles, gases, and vapors & & 21. Occupational noise & $0.71 \%(0.51 \%-0.93 \%)$ & $19.27 \%$ \\
\hline 22. Ergonomic risks & & 22. Drug use & $0.68 \%(0.55 \%-0.8 \%)$ & 65.42 \\
\hline 23. Occupational noise & $-\cdots$ & 23. Occupational particles, gases, and vapors & $0.67 \%(0.48 \%-0.86 \%)$ & $-26.45 \%$ \\
\hline
\end{tabular}

DALY: disability-adjusted life years

Figure 3B. Risk factors that most contributed to premature death and loss of health from chronic noncommunicable diseases among women aged 50 to 69. Brazil, 1990 and 2016.

\begin{tabular}{|c|c|c|c|c|}
\hline Women aged 50 to $69-1990$ & & Women aged 50 to $69-2016$ & $\%$ of the total DALY & Variation \\
\hline 1. High blood pressure & & 1. High body mass index & $17.1 \%(12.42 \%-21.97 \%)$ & $4.74 \%$ \\
\hline 2. High body mass index & & 2. High blood pressure & $14.67 \%(12.93 \%-16.59 \%)$ & $-28.94 \%$ \\
\hline 3. Smoking habit & & 3. High blood glucose & $10.73 \%(9.21 \%-12.35 \%)$ & $-5.96 \%$ \\
\hline 4. High blood glucose & & 4. Smoking habit & $9.34 \%(8.17 \%-10.61 \%)$ & $-34.47 \%$ \\
\hline 5. High total cholesterol & & 5. High total cholesterol & $6.63 \%(5.47 \%-7.87 \%)$ & $-35.48 \%$ \\
\hline 6. Vegetable deficient diet & & 6. Alcohol consumption & $3.98 \%(2.72 \%-5.52 \%)$ & $26.92 \%$ \\
\hline 7. Nutritional deficiency in nuts and seeds & & 7. Impaired kidney function & $3.86 \%(3.44 \%-4.32 \%)$ & $-2.63 \%$ \\
\hline 8. Particulate matter in the environment & & 8. Nutritional deficiency in nuts and seeds & $3.52(2.39 \%-4.78 \%)$ & $-27.58 \%$ \\
\hline 9. Fruit deficient diet & & 9. Vegetable deficient diet & $2.89 \%(1.54 \%-4.39 \%)$ & $-44.99 \%$ \\
\hline 10. Domestic air pollution & & 10. Particulate matter in the environment & $2.6 \%(1.98 \%-3.34 \%)$ & $-40.86 \%$ \\
\hline 11. Impaired kidney function & & 11. Sedentary lifestyle & $1.95 \%(1.11 \%-2.88 \%)$ & $-32.62 \%$ \\
\hline 12. Alcohol consumption & & 12. Occupational carcinogens & $1.95 \%(1.5 \%-2.42 \%)$ & $17.1 \%$ \\
\hline 13. Sedentary lifestyle & & 13. Fruit deficient diet & $1.93 \%(0.8 \%-3.3 \%)$ & -55.92 \\
\hline 14. Nutritional deficiency in Omega 3 & & 14. Unprotected sex & $1.75 \%(1.52 \%-1.99 \%)$ & $-26.21 \%$ \\
\hline 15. Unprotected sex & & 15. High sodium diet & $1.71 \%(0.0024 \%-4.84 \%)$ & $46.1 \%$ \\
\hline 16. Passive smoking & & 16. Nutritional deficiency in whole grains & $1.5 \%(0.4 \%-3 \%)$ & $-24.41 \%$ \\
\hline 17. Nutritional deficiency in whole grains & & 17. Nutritional deficiency in Omega 3 & $1.33 \%(0.51 \%-2.34 \%)$ & $-50.56 \%$ \\
\hline 18. Fiber deficient diet & & 18. Passive smoking & $1.27 \%(0.95 \%-1.61 \%)$ & $-42.51 \%$ \\
\hline 19. Occupational carcinogens & & 19. Fiber deficient diet & $1.19 \%(0.68 \%-1.84 \%)$ & $-36.11 \%$ \\
\hline 20. Lead exposure & & 20. Ergonomic risks & $1.06 \%(0.76 \%-1.42 \%)$ & $14.43 \%$ \\
\hline 21. High sodium diet & & 21. Drug use & $0.63 \%(0.52 \%-0.74 \%)$ & $61.56 \%$ \\
\hline 22. Ergonomic risks & & 22. Lead exposure & $0.61 \%(0.17 \%-1.13 \%)$ & $-51.33 \%$ \\
\hline 23. Diet high in trans fatty acids & & 23. Occupational noise & $0.46 \%(0.34 \%-0.59 \%)$ & $19.39 \%$ \\
\hline 24. Drug use & & 24. Domestic air pollution & $0.45 \%(0.34 \%-0.61 \%)$ & $-89 \%$ \\
\hline 25. Occupational noise & & & & \\
\hline
\end{tabular}

DALY: disability-adjusted life years 
they rose from 22nd to 18th position (Figure 3A), an increase of 30.7\%. Among women (1.06\%), the change went from 22nd to 20th position (Figure 3B), an increase of $14.43 \%$. The third occupational hazard is noise, which in 2016 rose from 23rd to 21st position among men, an increase of $19.27 \%$ if compared with 1990 (Figure 3A). Among women aged 50 to 69, the position changed from 25th (1990) to 23rd place (2016), an increase of 19.39\% (Figure 3B).

Aerodispersoids (gases, vapors, and particles in the environment) configured relevant RF only to men aged 50 to 69 in 1990. However, there was a decrease in this RF from 21st to 23rd position.

In summary, in 1990 and 2016, the main occupational RF for CNCD was ergonomic for both men and women aged 15 to 49 years. When analyzing the age group between 50 and 69 in 1990 and 2016, the main occupational hazard factor for CNCD for both sexes are occupational carcinogenic agents.

\section{DISCUSSION}

Using estimates from the GBD study, in 2016 there was an increase in the healthy years of life lost by CNCD attributable to occupational hazards in comparison with 1990 . The relevance of ergonomic risks, carcinogenic agents, and noise was not surprising, considering the known association between these occupational hazards and illnesses ${ }^{2,3,4,5}$. There is also evidence of the correlation between these risks and disease burden in other countries ${ }^{14,15,16}$. The differences observed when examining the healthy years lost according to sex confirm hypotheses attributable to the sexual division of labor ${ }^{17}$.

In Iran, ergonomic factors and noise topped the list of occupational hazards that had most contributed to the total DALY in $2015^{16}$. In Spain, occupational carcinogens ranked 12th in the ranking of environmental risks related to the total DALY in $2016^{15}$. In India, occupational hazards ranked third when calculating healthy years lost due to chronic obstructive pulmonary disease in $2016^{14}$. Disparities in comparisons can be attributed to a set of factors that vary from country to country - differences in the quality of national information systems, for example. In the Iranian study, estimates did not include exposure to carcinogenic trichloroethylene because this information was not available from any reliable source in the country ${ }^{16}$. Regarding the study carried out in Spain, Soriano et al..$^{15}$ presented a health situation summary according to the GBD study estimates for the country in 2016 for all 333 diseases and injuries, thus differing from our study, which focused only on CNCD. In the Indian study, estimates are exclusively related to chronic obstructive pulmonary disease (COPD) and asthma ${ }^{14}$. It is noteworthy that there should be necessary caution when interpreting disparities, once the specific limits that influence studies on respiratory diseases and other CNCD are known, such as the lack of consensus on case definition and the multiplicity of procedures involved in the application of spirometry, in addition to the bias arising from impediments in access to diagnostic services. At the technical level, complex procedures for the measurement of the exposed population are recommended when the disease presents a long latency period, as it happens with cancer. National capacities concerning such inputs also vary. Besides, errors in exposure assessment may influence the results of a national study ${ }^{18}$. This set of factors would explain the differences in estimates, at least in part. The limits of the GBD study will be presented ahead, which should be recalled when analyzing the contrast of inter-country results.

Macro-structural factors would explain the differences in the ranking of occupational hazards. National peculiarities regarding employment turnover and life expectancy are known, which influence the age at entry and exit to the workforce, with repercussions on the size and vulnerability of the population exposed to occupational carcinogens, for example. Despite disparities when comparing national results, consistency when 
examining correlated data (PS information on causes for work leaves, for example) is indispensable evidence for interpreting the results described. As mentioned, sickness allowances due to musculoskeletal causes, which are commonly associated with ergonomic factors in the adult population, predominated in $2016^{19}$. Thus, there is a coherence between disease burden attributable to ergonomic risks and musculoskeletal diseases as the first cause of work leave recognized and declared by the PS in 2016, as indicated by the results of our study.

Sex differences explain the workforce composition according to sex, which is called the sexual division of labor ${ }^{17}$. In Brazil, $15.6 \%$ of employed men were working in positions related to civil construction in 2014. Industries absorbed $17.2 \%$ of employed men, and $10.6 \%$ of employed women. In the service sector (education, health, and social services), the proportion was reversed: $4.3 \%$ of employed men, compared with $18.2 \%$ of women in this situation. Regarding employed women, the majority performed domestic services (13.9\%) or worked in the educational sector (7.4\%). Thus, despite the increasing participation of women in the workforce, they remain a minority in the heavy metallurgical industry, mining, construction, and agriculture, to name a few ${ }^{\mathrm{d}}$. This sexual division of labor reproduces male and female identity configurations. Men predominate in industries where tasks require more physical strength and contact with chemicals. Women are the majority in the service sector characterized by care-giving. In industry, they occupy positions in sectors characterized by the most thorough and repetitive operations, such as microelectronics ${ }^{17}$. This distribution of tasks and positions is expected to coincide with the distribution of exposure to occupational hazards specific to both sectors, which elucidates the differentials of the disease burden attributable to these risks according to $\operatorname{sex}^{20}$. Similarly, the ranking of occupational hazards was affected by sex in other countries as well ${ }^{14,15,16}$.

We observed a higher relevance in the ranking of risks regarding carcinogenic agents for men than for women, especially within the younger age group. Once again, the results are best interpreted based on the hypotheses of the sexual division of labor ${ }^{20}$ because most carcinogens found in the workplace are chemicals (asbestos, benzene, and organophosphates, for example), mainly handled in heavy metallurgy, mining, construction, and the agricultural sector, mostly composed of male workers ${ }^{4}$. The relevance of carcinogenic risks over other occupational hazards was observed regardless of sex within the age group between 50 and 69. The slow process of carcinogenesis triggered by continued occupational exposure to such agents ${ }^{e}$ could explain the progressive increase in incidence and mortality rates according to age for both men and women.

${ }^{\mathrm{d}}$ Departamento Intersindical de Estatística e Estudos Socioeconômicos (DIEESE). Anuário do Sistema Público de Emprego, Trabalho e Renda 2015: mercado de trabalho. São Paulo: DIEESE, 2015.

e Brasil. Ministério da Saúde. Secretaria de Vigilância em Saúde. Departamento de Vigilância Ambiental e Saúde do Trabalhador. Atlas do câncer relacionado ao trabalho no Brasil. Brasília. Ministério da Saúde, 2019. Disponível em: http://bvsms.saude.gov.br/bvs/ publicacoes/atlas_cancer_ relacionado_trabalho_brasil.pdf. Acesso 24 Fev 2019.

${ }^{f}$ WHO - World Health Organization. Global Health Risks: Mortality and burden of disease attributable to selected major risks. WHO: Geneva, 2009. Acesso 12 Set 2018.

Noise is the third occupational RF identified. The results are consistent with the World Health Organization classification ${ }^{\mathrm{f}}$, which ranks noise third among occupational hazards. Engines, pumps, ventilation systems, etc., are known for producing high intensity and low-frequency noise; mainly in the transport, industry, mining, construction, and agricultural sectors ${ }^{21}$. The effects of noise and extra-auditory function alterations induced by noise produced in facilities of the mentioned sectors, and others, are associated with the prevalence of CNCD among those exposed ${ }^{22}$.

Could the increase in the burden of illness attributable to occupational hazards for CNCD in 2016 be the effect of the period marked by institutional, social, and economic changes that modified working environments and employment bonds? At the institutional level, there has been a substantial transformation of social policies in Brazil in recent decades, leading to the advancement of knowledge and health care, including workers' health. The increase in access and improvement in the quality of information systems are the result of these policies, which favor the diagnosis of events and the registration of hazards ${ }^{1}$. It is possible, however, that the increased contribution of occupational hazards for the disease burden is, in line with the hypotheses of the present research, a consequence of the deterioration of working environments with innovations in production processes and precarious labor 
relations. At the macrostructural level, globalized capitalism with increasing frequency, confronting workers and jobs.

Changes in working environments with the introduction of new technologies, substances, and work processes are as fast as commercial design and the incentive for the consumption of new products worldwide ${ }^{23}$. This transformation is accompanied by exposure to new risks and increased exposure to risks already known?

Data available from the GBD study for Brazil enabled us to estimate the impact of occupational hazards on CNCD in Brazilian adults in an unprecedented way, using powerful and innovative metrics and constructs (DALY and PAR, for example), to circumvent some limits of classical studies ${ }^{6}$. By bringing together national data sources, especially household survey results, as well as satellite measurements, the GBD study created opportunities for researchers and public health professionals. However, it is important to inform the known limits of the GBD study. Risk estimates may be resulting in underestimation of the effect, and, therefore, of the load itself ${ }^{24}$. Firstly, it is known that national information on the number of exposed individuals and exposure levels is generally incomplete or nonexistent, either because of the heterogeneity of the workforce distribution or the diversity of arrangements in production sectors and subsectors in which exposure to multiple agents adds complexity to risk measurement ${ }^{4,7,25}$, as previously explained. Secondly, while monitoring for occupational hazard factors, environmental measurements, and periodic control of potentially exposed workers is provided for in the regulatory framework ${ }^{g}$, there are no information systems for occupational exposure in Brazil. Employment turnover and the effect of the healthy worker constitute, in the third place, another barrier, because there is a tendency to exclude those unhealthy to favor the demands of production. The turnover explains the exposure dispersion, given the fact that the worker will probably navigate between companies or sectors ${ }^{4,6,25}$. Also, it is internationally recognized that there is an insufficient intellectual, academic, and financial investment required to identify the occupational burden of disease. In this scenario of employment dynamics and information scarcity, the elaboration of workers' health surveillance measures is impaired, with repercussions on the chances of health deterioration?

The relevance of occupational hazards in the disease burden, as evidenced by the results presented, is in line with previous publications both in Brazil ${ }^{26}$ and in other countries ${ }^{14,15,16}$. The 12 national targets of the Strategic Action Plan to Combat Noncommunicable Chronic Diseases (2011-2022), however, do not include an approach for occupational exposure. The National Worker Health Policy , in turn, makes explicit the intention to align itself with the set of health policies within the Unified Health System, once work is admitted as one of the determinants of the health-disease process ${ }^{7,27}$. Unpublished results on the impact of CNCD attributable to occupational hazards are likely to raise debate about the desired occupational

g Brasil. Ministério da Saúde. Secretaria de Vigilância em Saúde. Departamento de Vigilância Ambiental e Saúde do Trabalhador. Atlas do câncer relacionado ao trabalho no Brasil. Brasília. Ministério da Saúde, 2019. Disponível em: http://bvsms.saude.gov.br/bvs/ publicacoes/atlas_cancer_ relacionado_trabalho_brasil.pdf. Acesso 24 Fev 2019.

h Brasil. Ministério da Saúde. Portaria $\mathrm{n}^{\circ} 1.823$, de 23 de agosto de 2012: Institui a Política Nacional de Saúde do Trabalhador e da Trabalhadora. Disponível em: http://bvsms. saude.gov.br/bvs/saudelegis/ gm/2012/prt1823_23_08_2012. html. Acesso em 24 Fev 2019. health actions crosscutting, and provide elements for shaping occupational-related axes in upcoming policy updates to monitor and prevent CNCD.

\section{CONCLUSION}

When analyzing the three groups of risk factors for DALY by CNCD in 1990 and 2016, there was a rise in the position of occupational hazards for both sexes concerning the other RF assessed by the GBD study. The emphasis given to occupational RF is probably related to structural changes in the labor market and production processes. The sexual division of labor explained differences in RF ranking according to gender. The results presented are in line with the current knowledge regarding the association between CNCD and occupational exposure; also converge with the causes of disability affecting adults covered by social security in the same period. Therefore, there should be a development of occupation-related pathways in future policy updates in order to monitor and prevent CNCD. 


\section{REFERENCES}

1. Malta DC, Bernal RTI, Nunes ML, Oliveira MM, Iser BPM, Andrade SSCA, et al. Prevalência de fatores de risco e proteção para doenças crônicas não transmissíveis em adultos: estudo transversal, Brasil 2012. Epidemiol Serv Saúde. 2014;23(4):609-622. doi: 10.5123/S1679-49742014000400003.

2. Fernandes RCP, Carvalho FM, Assunção AA. Prevalence of musculoskeletal disorders among plastics industry workers. Cad Saúde Pública. 2011, 27(1), 78-86. https://dx.doi.org/10.1590/S0102-311X2011000100008

3. Pimenta AM, Assunção AA. Thermal discomfort and hypertension in bus drivers and chargers in the metropolitan region of Belo Horizonte, Brazil. Appl Ergon. 2015; 47, 236-241.

4. ATRiBuíVEL F. Fração Atribuível a Fatores de Risco Ocupacionais para Câncer no Brasil: Evidências e Limitações. Rev Bras Cancer. 2016, 62(1), 43-45.

5. Braga LCD, Carvalho LRD, Binder MCP. Condições de trabalho e transtornos mentais comuns em trabalhadores da rede básica de saúde de Botucatu (SP). Cien Saude Col. 2010; 15: 1585-1596.

6. Castro TGMD, Lima EDP, Assunção AÁ (2019). Panorama dos inquéritos ocupacionais no Brasil (2005-2015): uma revisão sistemática da literatura. Cien Saude Col. 2019, 24: 2923-2932.

7. Schulte PA, Pana-Cryan R, Schnorr T, Schill AL, Guerin R, Felknor S, Wagner GR. An approach to assess the burden of work-related injury, disease, and distress. Am J Public Health. 2017;107(7): 1051-1057

8. Rzewuska M, de Azevedo-Marques JM, Coxon D, Zanetti ML, Zanetti ACG, Franco LJ, Santos JLF. Epidemiology of multimorbidity within the Brazilian adult general population: Evidence from the 2013 National Health Survey (PNS 2013). PLoSOne. 2017; 12(2), e0171813.

9. Murray CJL, Ezzati M, Flaxman AD, Lim S, Lozano R, Michaud C, et al. GBD 2010: design, definitions, and metrics. Lancet. 2012;380(9859):2063-6.

10. Institute for Health Metrics and Evaluation (IHME). Global Health Data Exchange. http://ghdx.healthdata.org

11. Marinho F, França EB, Cavalcante A. Carga da doença e análise da situação de saúde: resultados da rede de trabalho do Global Burden of Disease (GBD) Brasil. Rev Bras Epidemiol. 2017; 20 SUPPL 1: 1-3.

12. GBD 2016 Risk Factors Collaborators. Global, regional, and national comparative risk assessment of 84 behavioural, environmental and occupational, and metabolic risks or clusters of risks, 1990-2016: a systematic analysis for the Global Burden of Disease Study 2016. Supplementary appendix 1. Lancet. 2017;390(10100):1345-1422. doi:10.1016/S0140-6736(17)32366-8.

13. GBD 2016 DALYs and HALE Collaborators. Global, regional, and national disability-adjusted life-years (DALYs) for 333 diseases and injuries and healthy life expectancy (HALE) for 195 countries and territories, 1990-2016: a systematic analysis for the Global Burden of Disease Study 2016. Supplementary appendix. Lancet. 2017; 390(10100):1260-1344. doi:10.1016/S0140-6736(17)32130-X.

14. Salvi S, Kumar GA, Dhaliwal RS, Paulson K, Agrawal A, Koul PA, ... \& Christopher DJ. The burden of chronic respiratory diseases and their heterogeneity across the states of India: the Global Burden of Disease Study 1990-2016. The Lancet Global Health. 2018; 6(12), e1363-e1374.

15. Soriano JB, Rojas-Rueda D, Alonso J, Antó JM, Cardona PJ et al. La carga de enfermedad em España: resultados del Estudio de la Carga Global de lãs Enfermedades 2016. Med Clín. 2018; 151(5), 171-190.

16. Abtahi M, Koolivand A, Dobaradaran S, Yaghmaeian K, Khaloo SS et al. National and subnational mortality and disability-adjusted life years (DALYs) attributable to 17 occupational risk factors in Iran, 1990-2015. Environ Res. 2018; 165, 158-175.

17. Hosseinpoor AR, Williams JS, Amin A, Carvalho IA, Beard J, Boerma T, et al. Social determinants of self-reported health in women and men: understanding the role of gender in population health. PLoS One. 2012;7(4):e34799. doi: 10.1371/journal.pone.0034799.

18. Feigin VL, Roth GA, Naghavi M, Parmar P, Krishnamurthi R et al. Global burden of stroke and risk factors in 188 countries, during 1990-2013: a systematic analysis for the Global Burden of Disease Study 2013. Lancet Neuro. 2016;15(9), 913-924. 
19. Driscoll T, Jacklyn G, Orchard J, Passmore E, Vos T, Freedman G, et al. The global burden of occupationally related low back pain: estimates from the Global Burden of Disease 2010 study. Ann Rheum Dis. 2014;73(6):975-981. Epub 2014 Mar 24. doi:10.1136/annrheumdis-2013-204631. PubMed PMID: 24665117.

20. Messing K, Stellman JM. Sex, gender and women's occupational health: the importance of considering mechanism. Environ Res. 2006;101(2):149-162. doi:10.1016/j.envres.2005.03.015. PubMed PMID: 16709471.

21. Nelson DI, Nelson RY, Concha-Barrientos M, Fingerhut M. The global burden of occupational noise-induced hearing loss. Am J Ind Med. 2005; 48(6):446-458. DOI:10.1002/ajim.20223

22. Basner M, Babisch W, Davis A, Brink M, Clark C, Janssen S, et al. Auditory and non-auditory effects of noise on health. Lancet. 2014; 383(9925):1325-1332. doi:10.1016/S01406736(13)61613-X. PubMed PMID: 24183105; PubMed Central PMCID: PMC3988259.

23. Kalleberg AL (2018) Precarious work, insecure workers: employment relations in transition. Am Sociol Rev 74:1-22.

24. Rushton L. The global burden of occupational disease. Current Environ Health Reports. 2017; 4(3):340-348

25. Ribeiro FSN, Wünsch Filho V. Avaliação retrospectiva da exposição ocupacional a cancerígenos: abordagem epidemiológica e aplicação em vigilância em saúde. Cad Saúde Pública. 2004; 20: 881-890.

26. Malta DC, Felisbino-Mendes MS, Machado ÍE, Passos VMDA, Abreu DMXD, Ishitani LH, et al. Fatores de risco relacionados à carga global de doença do Brasil e Unidades Federadas, 2015. Rev Bras Epidemiol. 2017; 20:217-232. http://dx.doi.org/10.1590/1980-5497201700050018

27. Bambra C. Work, worklessness and the political economy of health inequalities. J Epidemiol Community Health. 2011; 65(9):746-750. DOl:10.1136/jech.2009.102103. 